\title{
Multiple-Locus Variable Number of Tandem Repeats Fingerprinting (MLVF) and Virulence Factor Analysis of Methicillin Resistant Staphylococcus aureus SCCmec Type III
}

\author{
MOHAMMAD EMANEINI ${ }^{1}$, LEILA JABALAMELI ${ }^{1}$, HOSSEIN IMAN-EINI ${ }^{2}$, MARZIEH ALIGHOLI ${ }^{1}$, \\ AMIR GHASEMI ${ }^{1}$, FARROKH AKBARI NAKHJAVANI ${ }^{1}$, MOROVAT TAHERIKALANI ${ }^{3}$, \\ BABAK KHORAMIAN ${ }^{1}$, PARISA ASADOLLAHI ${ }^{3}$ and FERESHTEH JABALAMELI ${ }^{* 1}$ \\ ${ }^{1}$ Department of Microbiology, School of Medicine, Tehran University of Medical Sciences. Tehran, Iran \\ ${ }^{2}$ School of ECE, College of Engineering, University of Tehran. Tehran, Iran \\ ${ }^{3}$ Department of Microbiology, School of Medicine, Ilam University of Medical Sciences, Ilam, Iran
}

Received 20 February 2011, revised 8 September 2011, accepted 10 September 2011

\author{
Abstract
}

\begin{abstract}
Methicillin resistant Staphylococcus aureus (MRSA), particularly strains with type III staphylococcal cassette chromosome mec (SCCmec), represent a serious human pathogen in Tehran, Iran. The disease-causing capability depends on their ability to produce a wide variety of virulent factors. The prevalence of exotoxin genes and multiple-locus variable number of tandem repeats fingerprinting (MLVF) profile among MRSA isolates, from patients in Tehran, was evaluated by PCR and Multiplex-PCR. The MLVF typing of 144 MRSA isolates with type III SCCmec produced 5 different MLVF types. Generally, 97.2\% (140/144) of all the isolates were positive for at least one of the tested exotoxin genes. The most prevalent genes were $h l d$, found in $87.5 \%(126 / 144)$ of the isolates followed by lukE-lukD and hla found in $72.9 \%$ $(105 / 144)$ and $70.1 \%(101 / 144)$ of the isolates, respectively. The tst gene, belonging to MLVF types I, IV and V, was found among three of the isolates from blood and wound samples. The sea gene was detected in 58.3\% (84/144) of the isolates and the sed and see genes were found in one isolate with MLVF type V. The coexistence of genes was observed in the 87.5\% (126/144) of the isolates. The rate of coexistence of hld with lukE-lukD, hla with lukE-lukD and sea with lukE-lukD were 66.7\% (96/144), 44.4\% (64/144) and 44.4\% (64/144), respectively. The present study demonstrated that MRSA strains with type III SCCmec show different MLVF patterns and exotoxin profiles.
\end{abstract}

Ke y word s: methicillin-resistant Staphylococcus aureus, MLVF, exotoxin

\section{Introduction}

Methicillin resistant Staphylococcus aureus (MRSA) is a nosocomial and community pathogen causing various infections, ranging from simple superficial skin infections to more life-threatening ones, including endocarditis, pneumonia, and toxic shock syndrome (Jarraud etal., 2002; Emaneini etal., 2007; Fatholahzadeh et al., 2008). Hospital-associated MRSA is usually accompanied by specific risk factors such as recent hospitalization, surgery, dialysis and long-term care. Risk factors for community-acquired infections include intravenous drugs, prior antimicrobial usage and underlying illnesses such as pulmonary disease, diabetesand chronic skin diseases (Moreno et al., 1995; Chambers, 1997; Baba et al., 2002). However, the capability of $S$. aureus strains to produce disease depends on its ability to create a wide variety of virulence factors that contribute to colonization and disease incidence in hosts (Dinges et al., 2000). Some S. aureus strains produce a variety of exotoxins such as staphylococcal enterotoxins (SEs), toxic shock syndrome toxin 1 (TSST-1), exfoliative (epidermolytic) toxins (ETs), several haemolysins (alpha, beta, gamma and delta) and Panton-Valentine leukocidin (PVL). Staphylococcal enterotoxins are responsible for staphylococcal food poisoning, whereas TSST-1 and ETs are the causative toxins of toxic shock syndrome and staphylococcal scalded-skin syndrome, respectively (Baba et al., 2002; Kim et al., 2006). PVL is involved in severe diseases among children and young adults with no apparent experience of reference to healthcare establishments (Holmes et al., 2005).

Many molecular methods have been used to determine the genotypic background of S. aureus isolates, including Pulsed-Field Gel Electrophoresis (PFGE)

\footnotetext{
* Corresponding author: F. Jabalameli, Department of Microbiology, School of Medicine, Tehran University of Medical Sciences; Tehran, Iran; e-mail: jabalamf@sina.tums.ac.ir
} 
considered as a "gold standard" to Multi-Locus Sequence Typing (MLST) and Spa typing. However, some limiting factors, such as financial expenses, have caused these methods to be used only in some laboratories. During recent years, PCR-based typing methods have been developed which are cheaper and less time consuming than PFGE or sequence-based typing. Multiple-Locus Variable Number of Tandem Repeats Fingerprinting (MLVF) is a new method used for characterization of $S$. aureus isolates which is based upon the detection of the number variation in short sequence repeats in seven individual genes (sspA, spa, clf $A, c l f B, s d r C, s d r D$ and $s d r E$ ). There are various reports suggesting that the production of staphylococcal toxins does vary according to genotype. Moreover, it has also been suggested that the staphylococcal toxin profiles of particular isolates may be influenced by their geographic origins (Moore et al., 2001; Baba et al., 2002; Banks et al., 2003).

A recent study has reported a high incidence of MRSA with SCCmec type III in Tehran (Fatholahzadeh et al., 2008). However, the properties of their virulence factors are unknown. This study was designed to determine the prevalence of different exotoxins and genotypes among the MRSA isolates, obtained from patients in Tehran.

\section{Experimental}

\section{Material and Methods}

MRSA Isolates. A total of 144 clinical isolates of MRSA with SCCmec type III were involved in the present study. These isolates were selected from a collection of 178 MRSA strains obtained from various nosocomial infection sites (wound, blood, respiratory, cerebrospinal fluid, pleural fluid, osteomyelitis, catheter-related infection, septicemia and urine) from patients who developed infections within the first $48 \mathrm{hr}$ of their admission to a hospital in Tehran. The collection process was carried out during April 2008 to March 2009 from different wards of the hospital. Only one isolate was investigated per patient. To confirm the identification of the isolate as MRSA, the fem $A$ and $m e c A$ gene were amplified by a PCR-based method, using primers femA-F-5'-AAA AAG CAC ATA ACA AGC G-3', femA-R-5'GAT AAA GAA GAA ACC AGC AG-3', mecA-F 5'-TGG CTA TCG TGT CAC AAT CG-3' and mecA-R 5'-CTG GAA CTT GTT GAG CAG AG-3' (Mehrotra et al., 2000). The MRSA isolates were confirmed as type III SCCmec using the method described by Oliveira et al. (Oliveira and de Lencastre, 2002). The WBG525 (EMRSA-1, SCCmec type III, ccr 3) strain were used as control.

Toxin gene detection. All the isolates were tested for the presence of genes encoding haemolysins (alpha, beta, gamma and delta), TST, ETA, ETB, SEA, SEB, SEC, SED, SEE, LUKE and LUKF by PCR and Multiplex - PCR using previously described primers (Mehrotra et al., 2000; Jarraud et al., 2002). S. aureus ATCC 14458, NCTC 7428 and ATCC 49775 were used as controls.

MLVF typing. The primers used to detect clfA, clfB, sdrCDE, spa, and sspA were as described by Sabat et al. (Sabat et al., 2003). The conditions of multiplex PCR were as described by Tenover et al. (Tenover et al., 2007) with some modifications, which are as follows; the PCR was performed in a final volume of $25 \mu \mathrm{L}$ containing 2 units of Taq DNA polymerase, $1 \mathrm{X}$ of PCR buffer, $0.2 \mathrm{mM}$ of each deoxynucleoside triphosphate, $2.5 \mathrm{mM} \mathrm{MgCl} 2,1 \mu \mathrm{mol} / \mathrm{ml}$ of ClfA-F/R, $0.6 \mu \mathrm{mol} / \mathrm{ml}$ of ClfB-F/R, CdrCDE-F/R, Spa-F/R, SspA-F/R and $6 \mu \mathrm{l}$ of DNA template. The cycles included $94^{\circ} \mathrm{C}$ for $5 \mathrm{~min}$ for the first cycle followed by 30 cycles of $94^{\circ} \mathrm{C}$ for $40 \mathrm{~s}$, $53^{\circ} \mathrm{C}$ for $40 \mathrm{~s}, 72^{\circ} \mathrm{C}$ for $1 \mathrm{~min}$ and a final cycle of $72^{\circ} \mathrm{C}$ for $5 \mathrm{~min}$. Amplified products were analyzed by electrophoresis on 2\% agarose gel. DNA bands were visualized by staining with ethidium bromide and photographed under UV illumination. MLVA profiles were analyzed visually using the criteria of Sabat et al. (Sabat et al., 2003). Any pattern differing by one or more bands was considered as a distinct type.

\section{Results and Discussion}

MRSA is a pathogen of serious notice in Tehran for being a cause of a wide variety of nosocomial infections. A high prevalence rate of MRSA with SCCmec type III was previously reported in this region (Fatholahzadeh et al., 2008). In order to identify the ability of MRSA strains to produce virulence factors, a population of 144 clinical MRSA isolates, causing a broad spectrum of infections, was investigated.

The MLVF typing of the 144 isolates produced 5 different MLVF types (Fig. 1). Ninety three isolates (64.6\%) were identified as type I, eighteen $(12.5 \%)$ as type II, fourteen $(9.7 \%)$ as type III, twelve $(8.3 \%)$ as type IV and seven isolates (4.9\%) as type V. The observation of different MLVF types among a single SCCmec type has not been previously reported. However, different MLVF types with identical PFGE patterns have been shown in the MRSA isolates (Moser et al., 2009). In the current study, the MRSA isolates belonged to a type of MLVF pattern that is widely distributed across various wards as well as among all the age groups of patients. This fact suggests that one major MRSA clone was circulated in the hospitals under assay. This was in agreement with the previous reports of other authors who had indicated that a few MRSA clones were predominant in nosocomial infections (Teixeira et al., 1995; Stefani and Varaldo, 2003). 


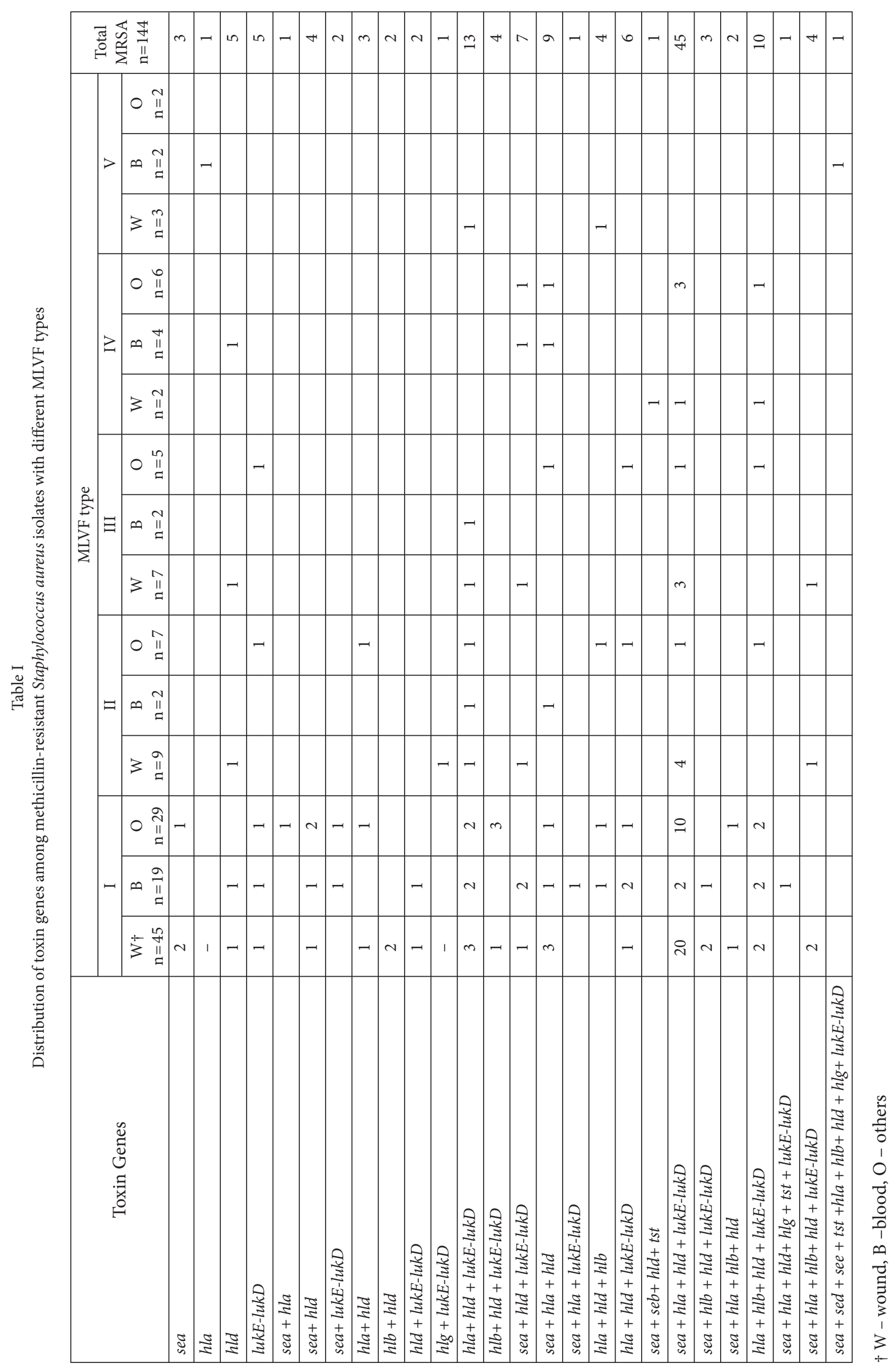




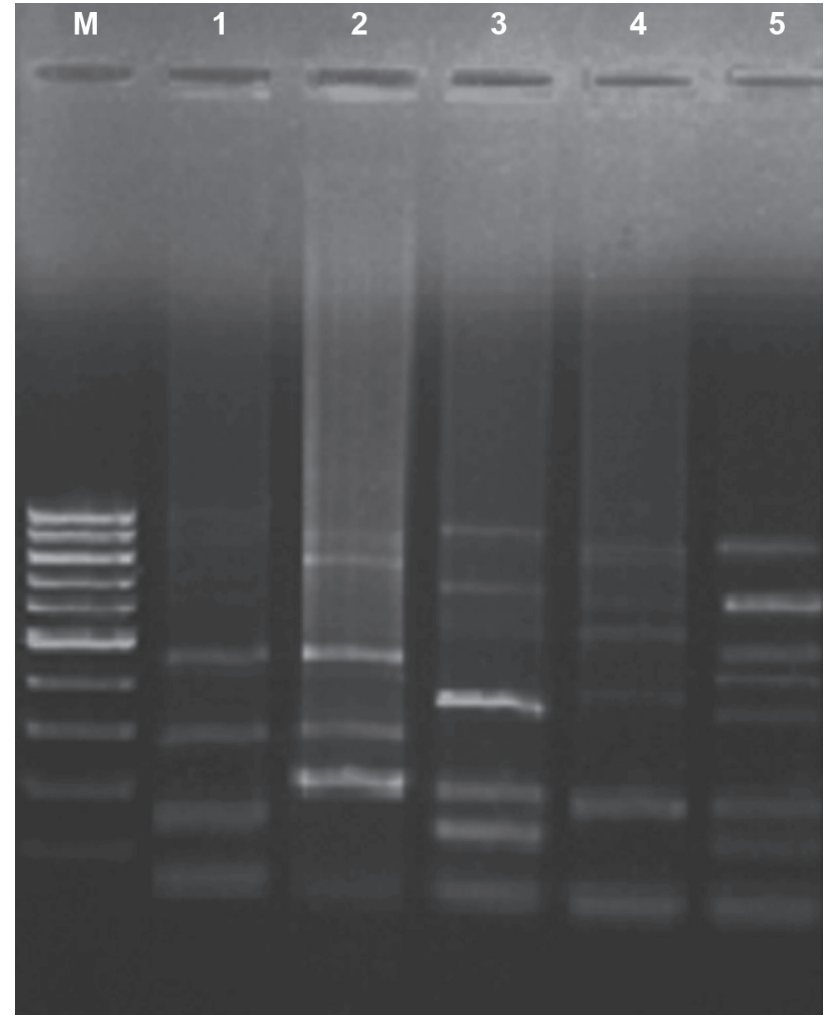

Fig. 1. Multiplex PCR MLVA typing of MRSA isolates. Lanes 1-5: tested MRSA isolates, identified as MLVA type I to V (lane 1; type II, lane 2; type III, lane 3; type IV, lane 4; type V, lane 5; type I).

The prevalence of the recognized genes among the studied isolates and the coexistence frequency of various virulence factors are summarized in Table I. Generally, $97.2 \%(140 / 144)$ of all the isolates were positive for at least one of the exotoxin genes tested. This was higher than the data reported by Kim et al. (Kim et al., 2006), who had found that $85.5 \%$ of the MRSA isolates produced one or more toxins.

S. aureus produces a number of cytotoxins including alpha, beta, delta and gamma hemolysins and Leukocidal toxin encoded by hla, hlb, hld, hlg, and lukE$l u k D$ genes respectively. These toxins are important in several staphylococcal diseases (Dinges et al., 2000). In the present study, the prevalence of these genes were $59 \%, 15.2 \%, 87.5 \%, 2.1 \%$ and $72.2 \%$, respectively. This contrasted the results obtained by Kocsis et al. (Kocsis et al., 2009) who reported a high prevalence rate of such genes among MRSA strains, isolated from Austria and Hungry. Although the genes encoding haemolysin toxins are located on chromosomes, the prevalence of these genes can be reduced by acquiring movable genes on genetic elements.

The prevalence of lukS-PV-lukF-PV gene among MRSA isolates differs noticeably in different countries (Jarraud etal., 2002; Karahan et al., 2008). In this study, all the isolates were negative for the lukS$P V$-lukF- $P V$ gene. This may be due to the fact that the tested isolates only carried the SCCmec type III. Other studies have shown that the gene encoding PVL is the molecular marker for community acquired-MRSA which usually carries type IV SCCmec element (Jarraud et al., 2002; Karahan et al., 2008).

The genes encoding SEs are carried on various genetic elements including phages (sea, see), plasmids (sed) and pathogenicity island (seb and sec) (Novick et al., 2001; Lawrynowicz-Paciorek et al., 2007). The present study also detected enterotoxin genes among $58.3 \%$ of the isolates. This shows a $16 \%$ lower rate than the data reported by Kim et al. (Kim et al., 2006) who reported that $74.4 \%$ of the MRSA isolates with SCCmec type III were positive for enterotoxin genes and that the sea genes were the most prevalent (58.3\%). However, the distribution pattern of the enterotoxin genes was different in the current study showing $74.4 \%$ sea and $48.8 \%$ see. In this study, the sec gene was not detected in any of the isolates and the seb gene was amplified in one isolate belonging to MLVA type IV from the wound associated with sea and tst genes. The sed and see genes associated with sea and $t s t$, were observed in one isolate obtained from the blood belonging to the MLVA type V.

Coexistence of genes was observed in $87.5 \%$ (126/144) of the isolates. The rate of coexistence of hld with lukE-lukD, hla with lukE-lukD and sea with lukElukD were $66.7 \%$ (96/144), 44.4\% (64/144) and $44.4 \%$ (64/144), respectively. The coexistence of sea with lukElukD, observed in this study, has also been reported by other studies (Schmitz et al., 1997; Gravet et al., 1999)

None of the MRSA isolates, in this study, were positive for the genes encoding the exfoliative toxin. This result is in agreement with other investigations showing a low prevalence rate of this gene among the tested isolates (Becker et al., 2003; Cha et al., 2006). As reported previously, only some strains of the S. aureus produce exfoliative toxins, whilst approximately all the isolates produce enzymes and hemolysins that contribute to their pathogenicity (Becker et al., 2003).

The tst gene encodes TSST-1, which is associated with staphylococcal toxic shock syndrome (TSS) and is considered to be the cause of nearly all cases of menstrual TSS and at least $50 \%$ of non-menstrual cases (Cha et al., 2006). Our results revealed that 3 isolates from blood and wound expressed the tst gene, in combination with other toxin genes. These isolates belonged to MLVF types I, IV and V.

Finally, it is concluded that the MRSA strains with type III SCCmec indicate different MLVF patterns and staphylococcal toxin profiles.

\section{Acknowledgment}

This research has been supported by Tehran University of Medical Sciences and Health Services grant 7243/87-03-30 which is acknowledged. 


\section{Literature}

Baba T., F. Takeuchi, M. Kuroda, H. Yuzawa, K. Aoki, A. Oguchi, Y. Nagai, N. Iwama, K. Asano, T. Naimi, H. Kuroda, L. Cui, K. Yamamoto and K. Hiramatsu. 2002. Genome and virulence determinants ofhigh virulence community-acquired MRSA. Lancet 359: 1819-1827.

Banks M.C., N.S. Kamel, J.B. Zabriskie, D.H. Larone, D. Ursea and D.N. Posnett. 2003. Staphylococcus aureus express unique superantigens depending on the tissue source. J. Infect Dis. 187: 77-86. Becker K., A.W. Friedrich, G. Lubritz, M. Weilert, G. Peters and C. Von Eiff. 2003. Prevalence of genes encoding pyrogenic toxin superantigens and exfoliative toxins among strains of Staphylococcus aureus isolated from blood and nasal specimens. J. Clin. Microbiol. 41: 1434-1439.

Cha J.O., J.K. Lee, Y.H. Jung, J.I. Yoo, Y.K. Park, B.S. Kim and Y.S. Lee. 2006. Molecular analysis of Staphylococcus aureus isolates associated with staphylococcal food poisoning in South Korea. J. Appl. Microbiol. 101: 864-871.

Chambers H.F. 1997. Methicillin resistance in staphylococci: molecular and biochemical basis and clinical implications. Clin. Microbiol. Rev. 10: 781-791.

Dinges M.M., P.M. Orwin and P.M. Schlievert. 2000. Exotoxins of Staphylococcus aureus. Clin. Microbiol. Rev. 13: 16-34.

Emaneini M., M. Aligholi, F.B. Hashemi, F. Jabalameli, S. Shahsavan, H. Dabiri, N. Jonaidi and K. Dahi. 2007. Isolation of vancomycin-resistant Staphylococcus aureus in a teaching hospital in Tehran. J. Hosp. Infect. 66: 92-93.

Fatholahzadeh B., M. Emaneini, G. Gilbert, E. Udo, M. Aligholi, M.H. Modarressi, K. Nouri, H. Sedaghat and M.M. Feizabadi. 2008. Staphylococcal cassette chromosome mec (SCCmec) analysis and antimicrobial susceptibility patterns of methicillin-resistant Staphylococcus aureus (MRSA) isolates in Tehran, Iran. Microb. Drug. Resist. 14: 217-220.

Gravet A., M. Rondeau, C. Harf-Monteil, F. Grunenberger, H. Monteil, J.M. Scheftel and G. Prévost. 1999. Predominant Staphylococcus aureus isolated from antibiotic-associated diarrhea is clinically relevant and produces enterotoxin A and the bicomponent toxin LukE-lukD. J. Clin. Microbiol. 37: 4012-4019.

Holmes A., M. Ganner, S. McGuane, T.L. Pitt, B.D. Cookson and A.M. Kearns. 2005. Staphylococcus aureus isolates carrying PantonValentine leucocidin genes in England and Wales: frequency, characterization, and association with clinical disease. J. Clin. Microbiol. 43: 2384-2390.

Jarraud S., C. Mougel, J. Thioulouse, G. Lina, Meugnier H., F. Forey, X. Nesme, J. Etienne and F. Vandenesch. 2002. Relationships between Staphylococcus aureus Genetic Background, Virulence Factors, agr Groups (Alleles), and Human Disease. Infect. Immun. 70: 631-641.

Karahan Z.C., A. Tekeli, R. Adaleti, E. Koyuncu, I. Dolapci and O.A. Akan. 2008. Investigation of Panton-Valentine leukocidin genes and SCCmec types in clinical Staphylococcus aureus isolates from Turkey. Microb. Drug. Resist. 14: 203-210.

Kim J.S., W. Song, H.S. Kim, H.C. Cho, K.M. Lee, M.S. Choi and E.C. Kim. 2006. Association between the methicillin resistance of clinical isolates of Staphylococcus aureus, their staphylococcal cassette chromosome mec (SCCmec) subtype classification, and their toxin gene profiles. Diagn. Microbiol. Infect. Dis. 56: 289-295.
Kocsis E., H. Lagler, N. Pesti, K. Stich, K. Kristóf, K. Nagy, P. Hermann, K. Komka, Z. Cekovska, W. Graninger and F. Rozgonyi. 2009. Comparison of Austrian, Hungarian and Macedonian methicillin-resistant and methicillin-sensitive Staphylococcus aureus strains in relation to prevalence of cytotoxin genes. Microb. Pathog. 46: 328-336.

M. Lawrynowicz-Paciorek, M. Kochman, K. Piekarska, A. Grochowska and B. Windyga. 2007. The distribution of enterotoxin and enterotoxin-like genes in Staphylococcus aureus strains isolated from nasal carriers and food samples. Int. J. Food. Microbiol. 117: 319-323.

Mehrotra M., G. Wang and W.M. Johnson. 2000. Multiplex PCR for detection of genes for Staphylococcus aureus enterotoxins, exfoliative toxins, toxic shock syndrome toxin 1 , and methicillin resistance. J. Clin. Microbiol. 38: 1032-1035.

Moore P.C. and J.A. Lindsay. 2001. Genetic variation among hospital isolates of methicillin-sensitive Staphylococcus aureus: evidence for horizontal transfer of virulence genes. J. Clin. Microbiol. 39: 2760-2767.

Moreno F., C. Crisp, J.H. Jorgensen and J.E. Patterson. 1995. Methicillin-resistant Staphylococus aureus as a community organism. Clin. Infect. Dis. 21: 1308-1312.

Moser S.A., M.J. Box, M. Patel, M. Amaya, R. Schelonka and K.B. Waites. 2009. Multiple-locus variable-number tandem-repeat analysis of meticillin-resistant Staphylococcus aureus discriminates within USA pulsed-field gel electrophoresis types. J. Hosp. Infect. 71: 333-339

Novick R.P., Schlievert P. and Ruzin A. (2001). Pathogenicity and resistance islands of staphylococci. Microbes. Infect. 3: 585-594.

Oliveira D.C. and H. de Lencastre. 2002. Multiplex PCR strategy for rapid identification of structural types and variants of the mec element in methicillin-resistant Staphylococcus aureus. Antimicrob. Agents. Chemother. 46: 2155-2161

Sabat A., J. Krzyszton-Russjan, W. Strzalka, R. Filipek, K. Kosowska, W. Hryniewicz, J. Travis and J. Potempa. 2003. New method for typing Staphylococcus aureus strains: multiple-locus variable-number tandem repeat analysis of polymorphism and genetic relationships of clinical isolates. J. Clin. Microbiol. 41: 1801-1804.

Schmitz F.J., C.R. MacKenzie, R. Geisel, S. Wagner, H. Idel, J. Verhoef, U. Hadding and H.P. Heinz. 1997. Enterotoxin and toxic shock syndrome toxin-1 production of methicillin resistant and methicillin sensitive Staphylococcus aureus strains. Eur. J. Epidemiol. 13: 699-708.

Stefani S. and P.E. Varaldo. 2003. Epidemiology of methicillin-resistant staphylococci in Europe. Clin. Microbiol. Infect. 9: 1179-1186.

Teixeira L.A., C.A. Resende, L.R. Ormonde, R. Rosenbaum, A.M. Figueiredo, H. de Lencastre and A. Tomasz. 1995 Geographic spread of epidemic multiresistant Staphylococcus aureus clone in Brazil. J. Clin. Microbiol. 33: 2400-2404.

Tenover F.C., R.R. Vaughn, L.K. McDougal, G.E. Fosheim and J.E. McGowan. 2007. Multiple-locus variable-number tandemrepeat assay analysis of methicillin-resistant Staphylococcus aureus strains. J. Clin. Microbiol. 45: 2215-2219.

von Eiff C., A.W. Friedrich, G. Peters and K. Becker. 2004. Prevalence of genes encoding for members of the staphylococcal leukotoxin family among clinical isolates of Staphylococcus aureus. Diagn. Microbiol. Infect. Dis. 49: 157-162. 